Escuela de Ciencias Sociales y Humanidades, UNED, Costa Rica https://revistas.uned.ac.cr/index.php/espiga ISSN: 1409-4002 • e-ISSN: 2215-454X

\title{
Fortalecimiento de la expresión escrita francés bajo modalidad colaborativa en el Colegio Técnico Profesional de Acosta
}

\section{Strengthening of French written expression under the modality collaborative at the Colegio Técnico Profesional de Acosta}

Développement de l'expression écrite chez les apprenants au niveau ai de la nèuvieme année du Colegio Técnico Profesional de Acosta 2020

César Efrén Morales-Conejo *

https://orcid.org/0000-0002-5833-2150

Recibido: 14 de marzo de 2021 • Aceptado: 16 de junio de 2021

* Magister en Administración Educativa, Universidad Estatal a Distancia (UNED). Licenciatura en la Enseñanza del francés, UNED. Licenciatura en Docencia, UNED. Bachiller en la Enseñanza del francés para secundaria, programa Universidad de Costa Rica-Universidad Estatal a Distancia, de Costa Rica Diplomado en Educación General Básica I y II Ciclo, Universidad San José, de Costa Rica. Trayectoria de 20 años como docente de francés en colegios públicos y privados. Voluntario de un programa lingüístico e intercultural de corrección fonética francesa con estudiantes de la Escuela de Formación Docente de la Universidad de Lávat, Quebec, Canadá. Correo: efrenmo12@gmail.com 


\section{Resumen}

Este artículo describe una propuesta pedagógica aplicada al alumnado de noveno año del Colegio Técnico Profesional (CTP) de Acosta en el 2019 para el desarrollo de la expresión escrita francesa mediante la elaboración de una revista temática. La finalidad de dicho proyecto fue impulsar a la persona estudiante para hacer uso correcto de las reglas gramaticales y de morfosintaxis del idioma francés en la redacción de artículos. Como dinámica de aula, se organizó al alumnado en equipos de trabajo y asumieron un rol como periodistas para la recopilación de información que sustentara dicho proyecto. Además en el proceso de evaluación formativa y sumativa, se establecieron los indicadores con la respectiva escala de calificación de contenidos tratados en clases de Francés Lengua Extranjera (FLE), cuyos resultados registraron un progreso significativo del alumnado en el dominio de la competencia lingüística seleccionada para la ejecución la investigación. Otro de los resultados alcanzados es el refuerzo de valores socioculturales de la población estudiantil al integrar su entorno social inmediato. Así mismo, se les concientizó acerca del manejo responsable de las nuevas Tecnologías de Información y Comunicación (TIC) para la redacción y publicación de contenido digital para medios virtuales. Entre las conclusiones, destaca la función docente de motivar al alumnado en el aprendizaje de un idioma extranjero, contribuir con la formación socioafectiva de la persona estudiante como futuro ciudadano global e impulsar el trabajo colaborativo, tendencia que ha tomado relevancia en el ámbito laboral.

Palabras clave: Tecnología educativa, producción escrita, trabajo colaborativo.

\section{Abstract}

This article describes a pedagogical proposal applied to ninth-year students of the Colegio Técnico Profesional (CTP) (Professional Technical College) of Acosta in 2019 for the development of French written expression through the preparation of thematic magazine. The purpose of this project was to encourage the students to make correct use of the grammar and from morphosyntax rules in French language when writing of magazine articles. As a classroom dynamic, the students were organized into work by teams and they assumed a role like journalists for the compilation of information to support said project. In addition, in the formative and summative process, the indicators were established with the respective rating scale of evaluation of contents traited in French language foreign classes, the results of which registered a significant progress of the students in the domain of the competence linguistic selected for the application of this investigation. Another of the results achieved is the reinforcement to socio-cultural values of the students population by integrating their immediate social environment. Likewise, they were made aware of the responsible management on the new Information and Communication Technologies (ICT) for the writing and digital content for virtual media. Among the conclusions, highlights the teaching function of motivating students to learn a foreign language, contributing to the socio-affective training as future global citizen and promoting the collaborative working, a trend that has become relevant in the workplace.

Keywords: Educational technology, team working, written production 


\section{Résumé}

Cet article décrit une proposition pédagogique appliquée à la population d'élèves de la neuvième année du Colegio Técnico Profesional (CTP) de Acosta pendant le cours 2009 pour le développement de l'expression écrite française à travers l'élaboration d'une revue thématique. Le but de ce projet est d'encourager l'apprenant à utiliser correctement des règles de grammaire et de morphosyntaxes de la langue française lors de la rédaction d'articles. Dans une dynamique de classe, les apprenants ont été organisés en équipes de travail et ils sont assumé un rôle de journalistes pour la compilation d'information à l'appui de ce projet. De plus, dans le processus d'évaluation formative et sommative, les indicateurs ont été établis avec l'échelle de notation respective des couverts dans le cours de classe français langue étrangère (FLE), dont les résultats ont registré une progression significative des étudiants dans le domaine de la compétence linguistique sélectionnée. Un autre des résultats atteints est le renforcement des valeurs socioculturelles de la population d'élèves en intégrant leur environnement social immédiat. De même, ils ont été sensibilisés a la gestion responsable des nouvelles Technologies d'Information et de Communication (TIC) pour la rédaction et publication de contenu digital par moyens virtuels. Parmi les conclusions, met en évidence la fonction pédagogique de motiver les apprenants à maîtriser la langue française à travers la production écrite et de renforcer le travail collaboratif, aspect privilégié qui a pris relevance dans la sphère du travail et comme partie de leur préparation et formation socio-affective, étant ils, les futurs citoyens de l'actuelle société globalisée et digitale.

Mots-clés: Éducation technologique, production écrite, travail collaboratif. 


\section{Introducción}

Como Trabajo Final de Graduación (TFG) para optar por la licenciatura en la Enseñanza del francés en la Universidad Estatal a Distancia (UNED), se confecciona y aplica una actividad pedagógica cuyo objetivo fue fortalecer las habilidades lingüísticas de la expresión escrita en Francés Lengua Extranjera (FLE) en el alumnado de noveno año del Colegio Técnico Profesional (CTP) de Acosta.

Esta institución educativa se ubica en San Ignacio, distrito central del cantón de Acosta, el número 12 de la provincia de San José, Costa Rica. Esta región se caracteriza por su topografía irregular en los $342,24 \mathrm{~km}^{2}$ que la componen, es uno de los cantones de mayor extensión del país.

El Liceo de Acosta se funda en 1966; en 1977 cambia su modalidad académica a técnica con el fin de que la población estudiantil se titule como Bachiller en Educación Media y se acredite en alguna especialidad como Técnico Medio, su oferta educativa se ha ampliado de acuerdo con las demandas del mercado laboral.

\section{Figura 1}

Mapa físico del cantón de Acosta

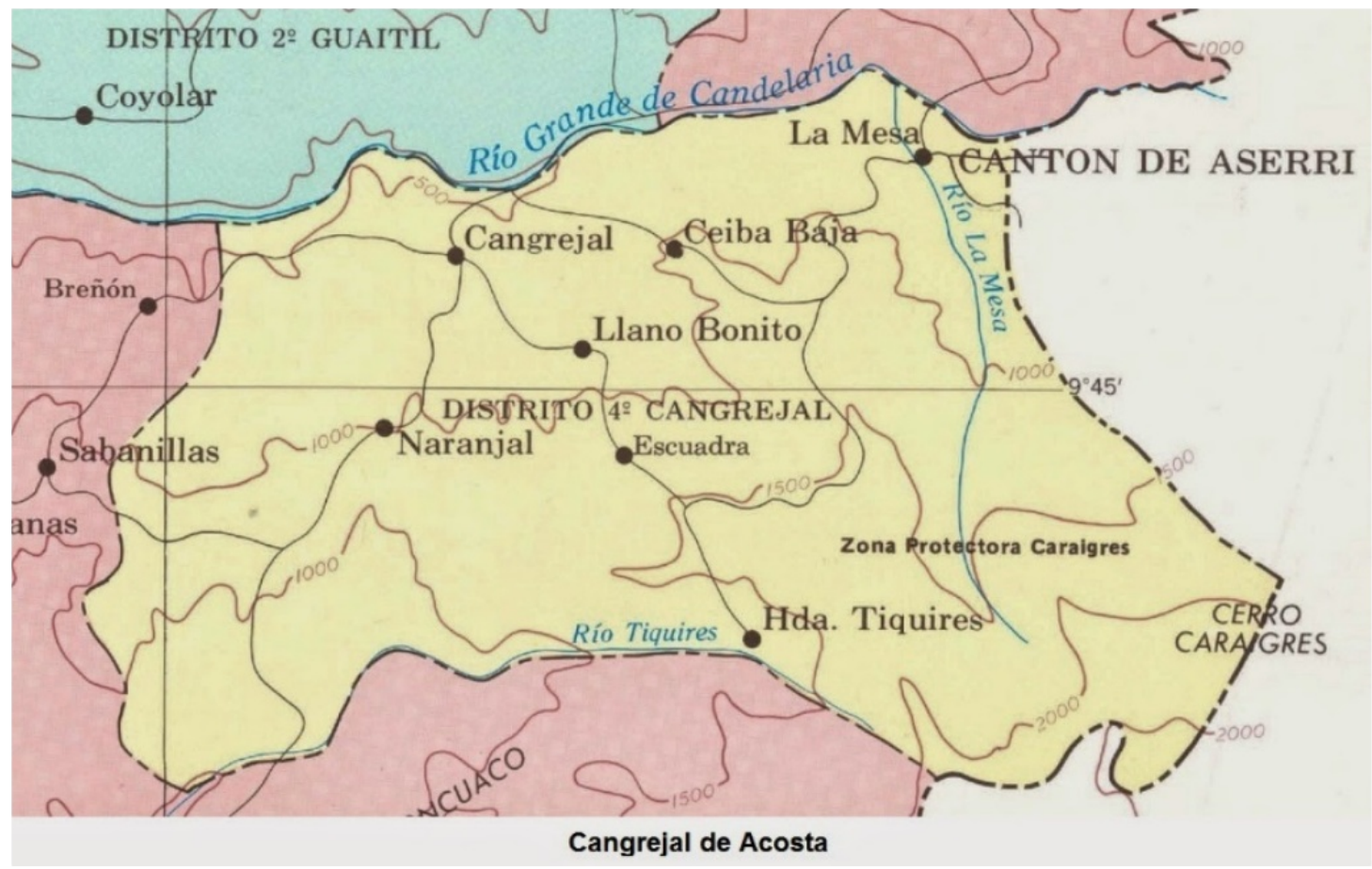

Fuente: http://1.bp.blogspot.com/-4vxJcXqKK4o/VCuLsDZPRbl/AAAAAAAAq6s/ ccCBdythTmo/s1600/ 
Acosta es reconocido por sus paisajes naturales, costumbres y tradiciones. Por años, su economía se basó principalmente en la actividad agrícola, la cual ha venido en descenso por el cambio generacional, cuyas aspiraciones laborales son muy distintas a las de sus antecesores.

Uno de los problemas más serios que azota la región es el faltante de fuentes de empleo, situación que ha obligado a muchos de sus pobladores a desplazarse o mudarse fuera de su comunidad para estar próximos a sus lugares de trabajo, lo que hace de este cantón un «pueblo dormitorio».

\section{Medios de comunicación digital y la enseñanza del francés en secundaria}

Con el fenómeno de la globalización y el acceso público a las nuevas Tecnologías de la Información y Comunicación (TIC), a quienes integran la Generación Z (nacidos a partir de 1995) se les conoce como «nativos digitales», ya que mantienen contacto directo con recursos tecnológicos desde temprana edad.

Esta revolución mediática ha hecho que el sistema educativo costarricense se adapte a los estándares y parámetros de una sociedad globalizada. Por esta razón, se ha ido incorporando el uso de las TIC en el proceso de enseñanzaaprendizaje como parte del cumplimiento de la agenda mundial.

Dispositivos de conectividad como los teléfonos móviles, las computadoras, las tabletas y la conexión a internet han facilitado y agilizado el manejo e intercambio de datos en tiempo real, lo que les vuelve de uso obligatorio para el desarrollo de actividades de índole humano y comercial.

El Ministerio de Educación Pública (MEP), por su parte, ha establecido alianzas y convenios con distintas entidades gubernamentales y privadas para dotar de medios tecnológicos a centros educativos y hogares del alumnado para fines educativos como estrategia, esto para ir reduciendo paulatinamente la brecha digital marcada entre los distintos sectores del país.

La lengua francesa es el primer idioma extranjero en formar parte de la malla curricular en la Educación Media; en el 2016 se renueva su programa de estudios cuyo enfoque va dirigido a la interculturalidad y a su aplicación desde una perspectiva accional.

De acuerdo con el Ministerio de Relaciones Exteriores y Culto, Costa Rica inicia relaciones diplomáticas con Francia el 12 de mayo de 1848, mediante la firma del tratado Toledo-Baradere. Para el 2014, Costa Rica se integra a la Organización Internacional de la Francofonía (OIF) como miembro observador, siendo sede la Embajada de Francia, la Alianza Francesa, la Asociación Costarricense de Profesores de Francés (ACOPROF) y el Liceo FrancoCostarricense. 
La enseñanza del idioma francés se mantiene vigente en centros educativos de primaria y secundaria. A nivel universitario, se concentra en la formación bilingüe para responder a situaciones en el ámbito social, cultural y profesional.

Se establece que la planificación de una mediación pedagógica para la enseñanza de un idioma extranjero esté contextualizada con el entorno sociocultural de la población estudiantil, así como la propuesta de actividades pedagógicas que brinden un valor funcional en su adquisición cognitiva como medio de comunicación y el establecimiento de relaciones interculturales.

La expresión escrita es una las competencias lingüísticas que conforman el FLE, la cual permite plasmar ideas e información a través de la redacción y la escritura, así como el reconocimiento y la aplicación correcta de las reglas gramaticales y de morfosintaxis.

El proceso de diagnóstico docente es una herramienta que permite identificar y registrar las condiciones de la institución educativa y de la comunidad en general con el propósito de contemplar y seleccionar aquellos métodos de enseñanza y recursos materiales que satisfagan las necesidades cognitivas y socio-afectivas del alumnado para ofrecer un servicio educativo de calidad, ajustado a su realidad.

\section{Desarrollo. Revista temática en Francés Lengua Extranjera (FLE)}

La elaboración de una revista temática fue la actividad pedagógica propuesta y desarrollada en la tesis del autor del presente artículo, «Développement de l'expression écrite chez les apprenants au niveau Al de la neuvième année du Colegio Técnico Profesional de Acosta 2020», disponible en la biblioteca virtual de la UNED, cuyo contenido evidencia el trabajo hecho por el estudiantado de noveno año (generación 2019) para la redacción de textos, de manera colaborativa, mediante el uso de recursos tecnológicos.

Como fase inicial, la persona docente motiva al alumnado mediante una presentación de clase en PowerPoint, donde detalla el «qué», «por qué» y «para qué» del aprendizaje del idioma francés como medio de comunicación en distintos escenarios sociales o laborales que se susciten a corto, mediano o a largo plazo.

Al inicio, la persona docente expone los lineamientos e indicadores de evaluación de dicho proyecto propuesto, poniendo en marcha acciones como la recopilación de datos y la elaboración de un plan de clase que detalle los objetivos, las actividades pedagógicas, los recursos materiales, los rubros de evaluación y el tiempo requerido para la distribución y ejecución de las tareas que el estudiantado llevará a cabo. 


\section{Figura 2}

Recurso visual utilizado en el proceso de motivación para la elaboración de una revista temática

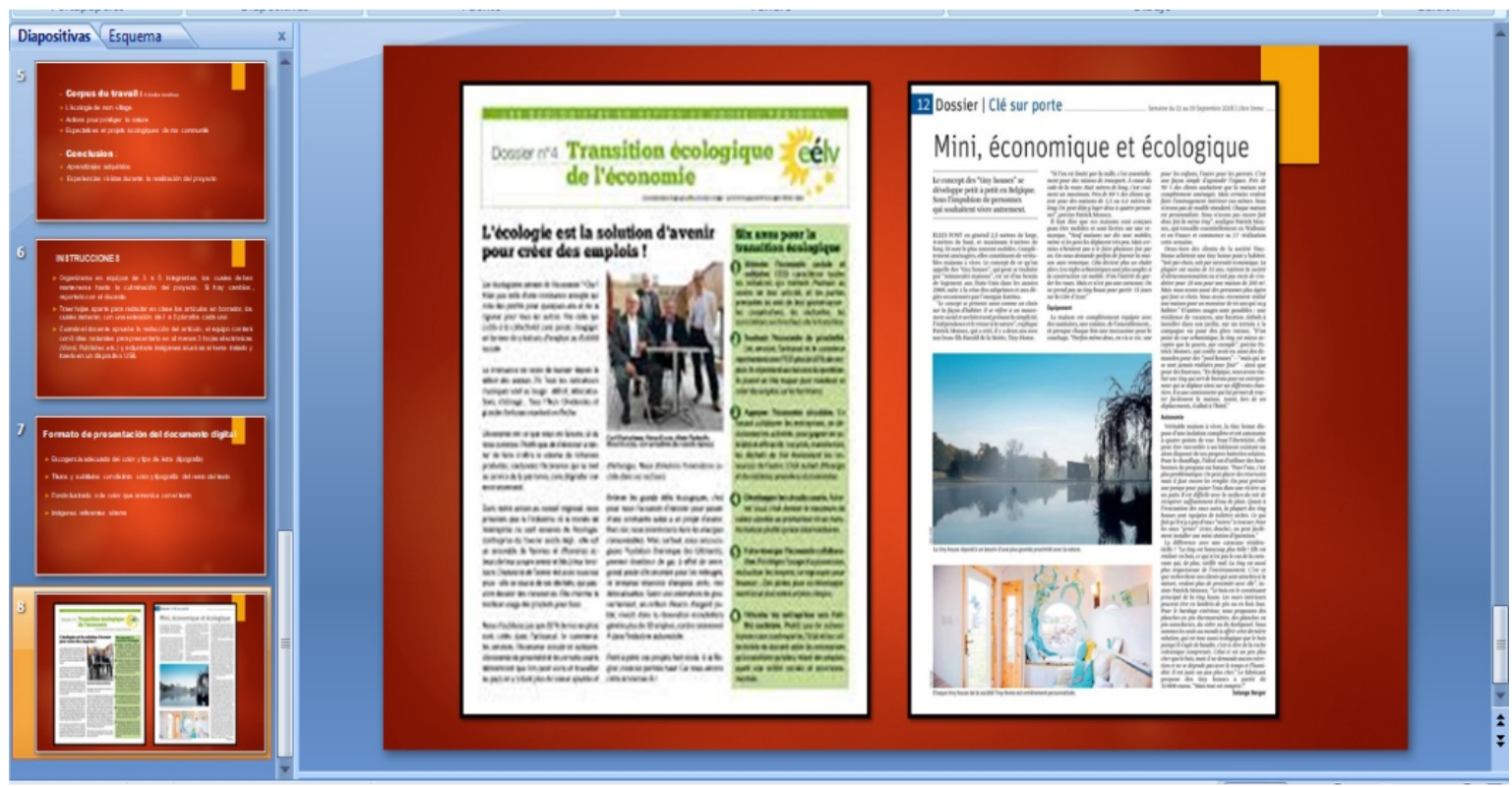

Fuente: Estrategia educativa aplicada al estudiantado de noveno año del Colegio Técnico Profesional de Acosta.

Tagliante afirma que «la proximidad comunicativa de la enseñanza de idiomas postula que para que el alumnado pueda comunicarse en idioma extranjero, debe brindársele los medios para constituir un bagaje personal de herramientas lingüísticas que le permita alcanzar sus objetivos de aprendizaje» ${ }^{1}$ (traducción libre). Como estrategia pedagógica, el docente puede enfocar su labor docente al contemplar la realidad inmediata del estudiantado para que su aprendizaje sea interiorizado, signigicativo y signifique una perspectiva accional.

La recolección y el análisis de datos obtenidos en el diagnóstico docente revelaron que temáticas como los recursos naturales y el desarrollo sostenible se encuentran entre los de mayor preferencia en el alumnado de noveno año, ya que forman parte de su folclor y costumbres de vida.

Como parte de la redacción de la revista temática propuesta, se encuentra la aplicación de entrevistas a miembros de la comunidad y a grupos dedicados a la protección del ambiente, donde el alumnado trasladará sus anotaciones al idioma francés, haciendo uso de las habilidades lingüísticas para la descripción de contenidos, propuestas y transmisión de opiniones.

${ }^{1}$ Christine Tagliante, L'évaluation et le Cadre Commun Européen. Techniques et pratiques de classe (Paris: CLE international, 2005), 33. 
Figura 3

Ejemplo de una revista para jóvenes como modelo de trabajo en clases de FLE

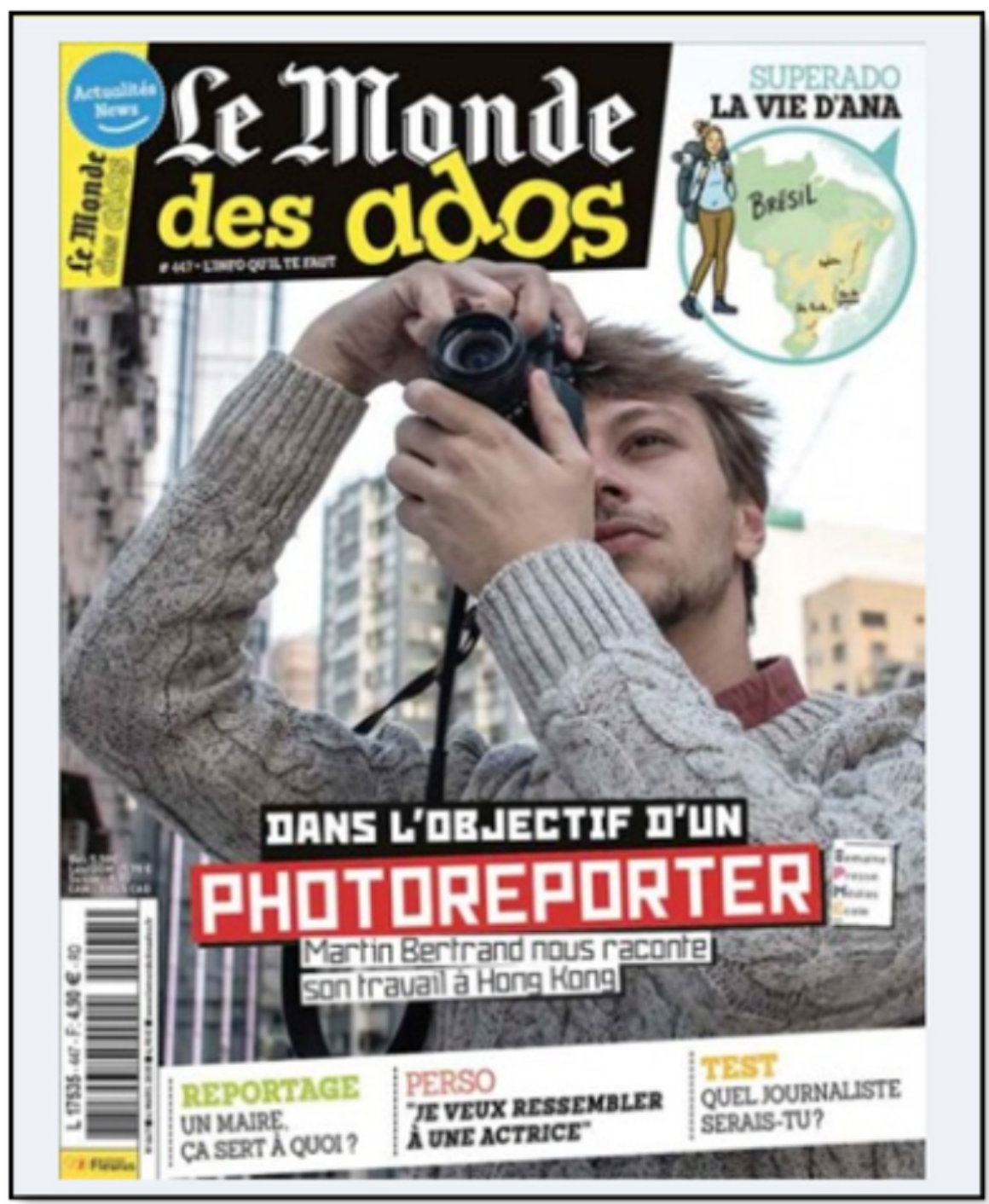

Fuente: Le monde des ados, https://www.fleuruspresse.com/magazines/ados/lemonde-des-ados\#!

Como parte de su labor, la persona docente proporciona el vocabulario y recurso de apoyo relacionado con la temática ecológica y de complemento, como adjetivos calificativos, colores, conectores, conjugación de tiempos verbales, la formación del imperativo, entre otros, para enriquecer la redacción de los artículos que contendrá dicha revista.

De acuerdo con Sugar, citado por Agama y Martínez, la revista es un medio de comunicación impreso donde el autor es capaz de expresar, denunciar e informar ${ }^{2}$. En el ámbito educativo, la persona docente puede proponer temáticas

2 Emily Agama y Alejandro Martínez, «El fotoperiodismo y los medios de comunicación impresos de la Ciudad de Ambato, Ecuador» (trabajo de graduación previo a la obtención de título de Licenciatura en Comunicación

Social, Universidad Técnica de Ambato, 2016), 74.

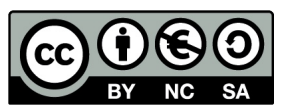




\section{Figura 4}

Ejemplo de portada de revista hecha por el alumnado de noveno año del colegio Técnico Profesional de Acosta

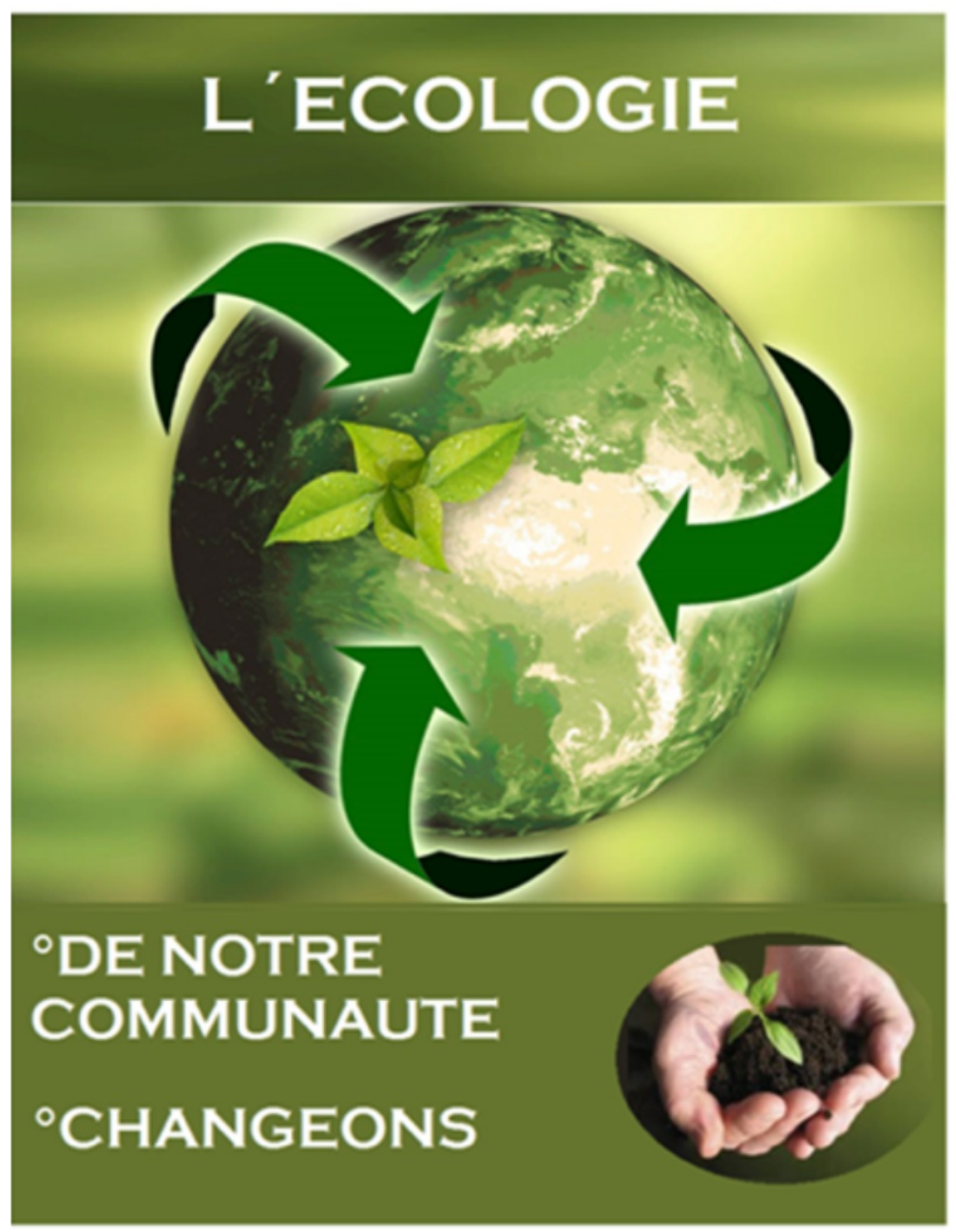

Fuente: Estrategia educativa aplicada al estudiantado de noveno año del Colegio Técnico Profesional de Acosta.

contextualizadas a la realidad del estudiantado, enfocadas en su preparación académica y profesional en áreas como el turismo verde o el emprendimiento mediante la elaboración de productos hechos con material de reciclaje 0 biodegradable.

La revista fue confeccionada en formato digital como parte del mensaje ecológico que involucra la eliminación o reducción en el uso del papel, uno de los daños de alto impacto contra el ambiente.

Al estudiantado se le proporcionó los pasos, normas y sugerencias para la estructuración e integración de imágenes y texto recopilados en las entrevistas e investigaciones para el posterior proceso de edición y presentación de la revista. 
Durante ese proceso, el estudiantado fue adquiriendo la capacidad lingüística para redactar párrafos y columnas de mayor extensión y con un mensaje concreto donde anteriormente utilizaba respuesta corta con poca claridad en sus ideas. La persona docente de FLE mantiene un sistema de evaluación más ligado con los contenidos y objetivos propuestos, así como de mayor soporte para la revisión y corrección de errores ortográficos y gramaticales detectados en las etapas preliminares.

El proyecto propuesto fue llevado a cabo de manera bimodal, donde el estudiantado va cumpliendo unas etapas de trabajo en clase y otras fuera del horario lectivo. En la presencialidad, los subgrupos de estudiantes se rigen bajo un cronograma de actividades para el desarrollo, culminación y entrega del producto final al docente, con una fecha límite de entrega.

Para la producción escrita, el Cuadro Común Europeo de Referencia hace hincapié que el alumnado tiene la libertad de traer consigo dispositivos tecnológicos para agilizar el proceso de redacción y corrección de texto 3 , por eso es imperativo que la persona docente supervise y brinde el apoyo requerido para la aplicación de los contenidos. Fuera de horario lectivo, el alumnado es el responsable de la recopilación de información, la toma de imágenes y fotografías en de sus comunidades, las cuales serán aparte de la revista digital.

Por lo tanto, la persona docente buscará alternativas y medios requeridos para «elaborar actividades dinámicas que sean de interés para los estudiantes en función de sus situaciones de su vida cotidiana» ${ }^{4}$ y refuerza su rol de guía al acompañar, supervisar y asesorar los distintos equipos de trabajo en actividades digitales como la manipulación de imágenes, la rotulación de textos y el uso adecuado de herramientas digitales como el traductor de Google y el paquete de Office, entre otras.

Courtillon resalta tres grandes variables que le permiten a la persona docente adaptar el proceso de enseñanza, entre ellas la naturaleza, las características de la población estudiantil, los objetivos de aprendizaje y la relación entre la lengua extranjera con la lengua materna ${ }^{5}$, todo esto en aras de satisfacer las necesidades cognitivas y socioculturales del estudiantado.

Gracias a la motivación y el apoyo pedagógico docente brindado, el alumnado logró redoblar esfuerzos en la aplicación de conocimientos, haciendo uso de la creatividad y demás talentos, con la oportunidad de crear, plasmar brindar y compartir ideas a través de la expresión escrita FLE, lo cual representa una experiencia significativa para el nivel de noveno año en el proceso de aprendizaje de un idioma extranjero.

\footnotetext{
3 Conseil de l'Europe, Cadre Européen Commun de Référence pour les Langues: Apprendre, Enseigner, Evaluer. (Strasbourg; Unité de Politique linguistiques 2001).

${ }^{4}$ Jessica Araya, «Estrategia didáctica para el trabajo colaborativo por medio de una red virtual de aprendizaje, con estudiantes de sétimo año del Colegio Miravalles del Circuito Escolar 04 de la Dirección Regional de Educación de Cartago, durante el curso lectivo 2011» (Tesis de Licenciatura), Universidad Estatal a Distancia, 2015,76 .
} 


\section{Figura 5}

El uso de imágenes tomadas por el alumnado de noveno año contrasta con la temática de la revista

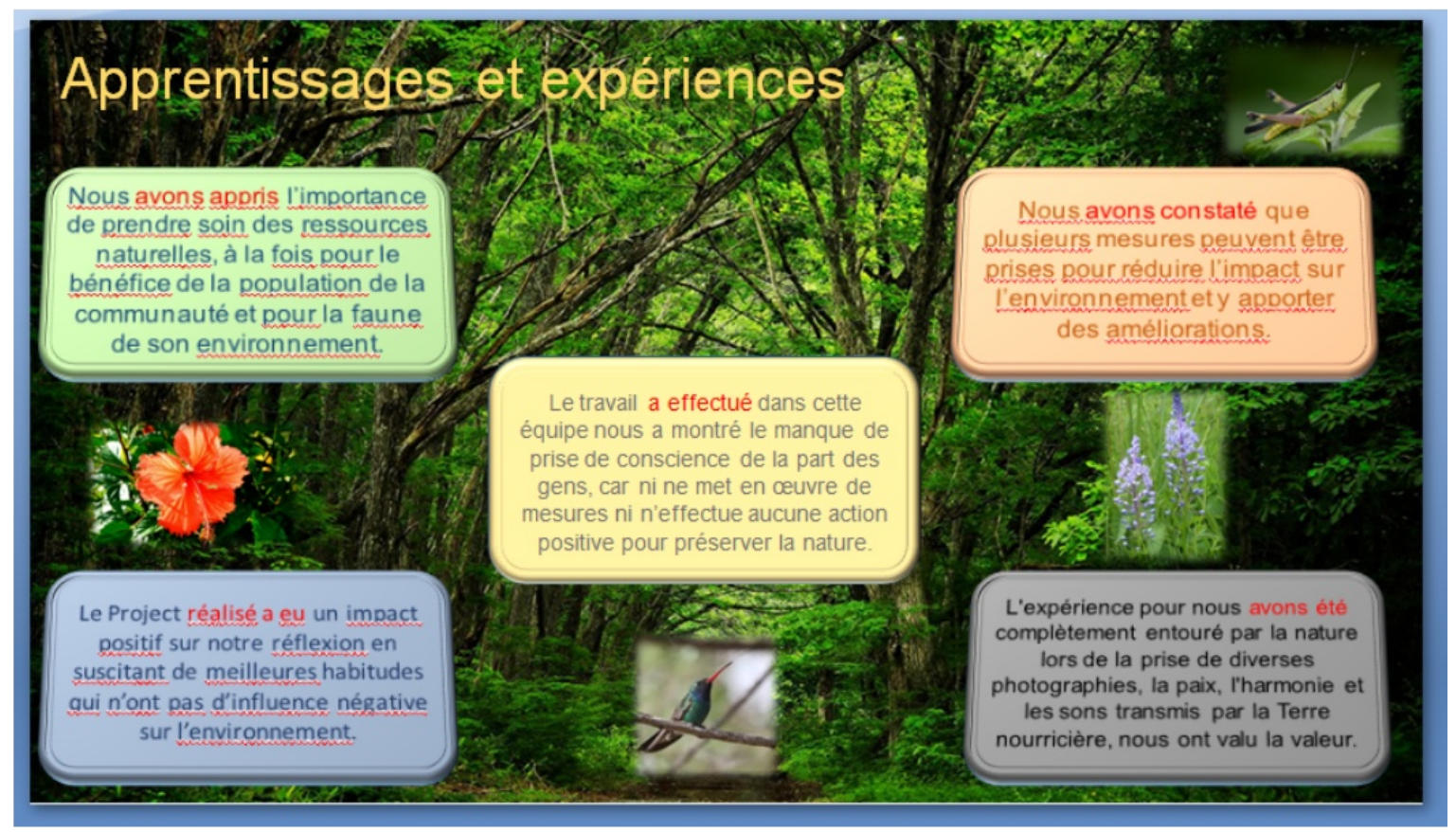

Fuente: Estrategia educativa aplicada al estudiantado de noveno año del Colegio Técnico Profesional de Acosta.

Para la correcta ejecución de esta propuesta educativa, quienes integran cada subgrupo asumieron una tarea específica de acuerdo con sus capacidades individuales y colectivas, como la puesta en práctica de las habilidades lingüísticas y digitales adquiridas previamente para el desarrollo de la expresión escrita francesa.

La persona docente dejó a libre elección del alumnado la conformación de equipos y la escogencia de los representantes líderes, encargados de velar por el orden y la participación de sus integrantes; en caso de no cumplirse las condiciones idóneas, la persona docente le corresponderá la organización de los equipos de clase de acuerdo con sus capacidades y habilidades íntegras.

En clase, la intervención de la persona docente fue clave en el establecimiento de protocolos para la resolución de conflictos y situaciones que pudiesen afectar el cumplimiento de objetivos.

Gracias a este proyecto, el aprendizaje y la aplicación dinámica de la expresión escrita francesa adquirió un valor funcional en el estudiantado como medio de comunicación, al evidenciar aspectos fundamentales como el reforzamiento de valores sociales, normas de convivencia y el espíritu colaborativo.

5 Janine Courtillon, Élaborer un cours de FLE (Paris: Éditorial Hachette, 2003), 11. 
Figura 6

Descripción de sitios naturales mediante la redacción de frases descriptivas

\section{Corteza Amarilla}

C'est un arbre caractéristique des zones chaudes, ses

fleurs sont jaunes et sa saison de floraison est à la fin de

la saison sèche en mars.

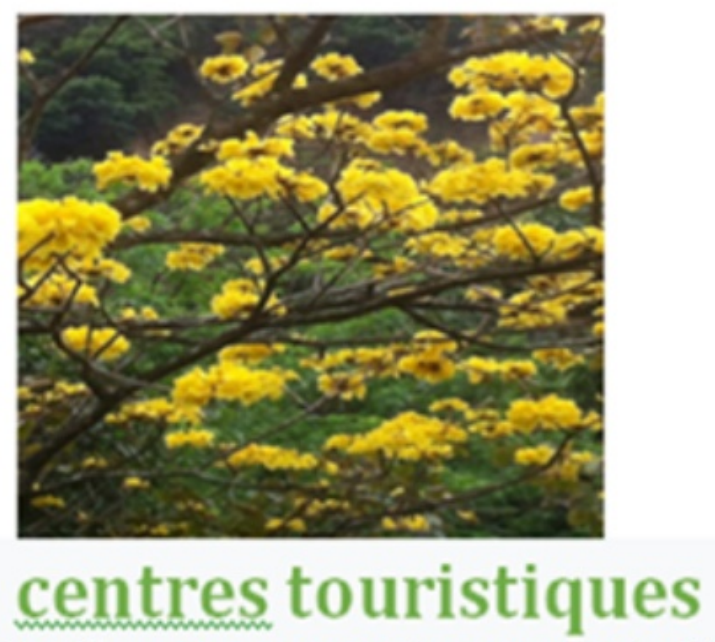

Dans cette ville, nous pouvons trouver des traités attrayents sur sa belle écologie.

Paraiso del rio

C'est un spa situé dans le glissement d'Acosta.

Il est entouré par la nature et beaucoup de paix.

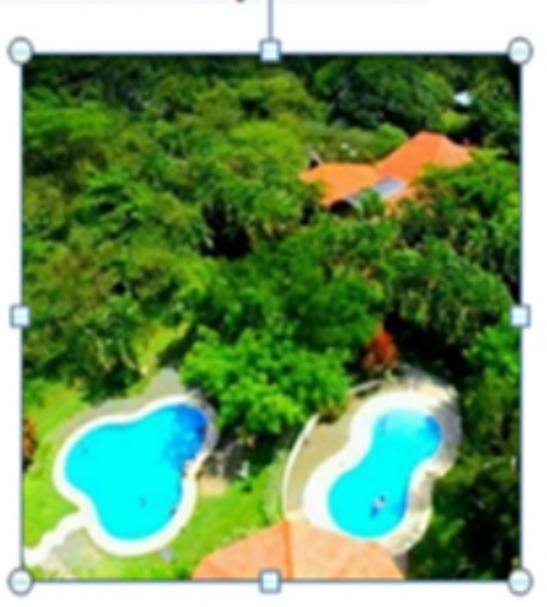

Fuente: Estrategia educativa aplicada al estudiantado de noveno año del Colegio Técnico Profesional de Acosta.

Baudrit, citado por Mignot, resalta que el trabajo colaborativo se postula «como la actividad colectiva orientada a una misma dirección, hacia un objetivo compartido por todos, puede aprovechar a cada miembro del grupo por sus adquisiciones» ${ }^{6}$. Este proyecto pretende que los miembros de cada subgrupo apliquen las habilidades lingüísticas adquiridas en clase para la elaboración de un trabajo de producción escrita. 
Drouin et al. ${ }^{7}$ señalan que la pedagogía cooperativa tiene la particularidad de fundarse en valores cooperativos: Respeto, ayuda mutua, apertura a otros, compromiso, derecho a la diferencia, solidaridad, etc.

En conjunto, el alumnado mostró mayor interés y esfuerzo por apropiarse de la competencia escrita en FLE, en aras de desarrollar capacidades interdisciplinarias y de la adquisición de habilidades blandas que les facilite su desenvolvimiento en el ámbito social, laboral e intercultural.

\section{Conclusiones}

La independencia lingüística es una de las fortalezas del proyecto desarrollado en el CTP de Acosta, al registrar un esfuerzo y entusiasmo por parte del alumnado de noveno año y de la persona docente, al obtener como resultado final un aprendizaje significado en la aplicación de un idioma extranjero en espacios de corte social y profesional.

Es imprescindible que el trabajo de aula genere experiencias educativas significativas en la población estudiantil y correlacionen los contenidos de clase con su contexto socio-cultural, además del reforzamiento de valores sociales como el respeto, la tolerancia y la equidad, los cuales deben prevalecer en toda institución educativa.

El uso de dispositivos tecnológicos y la virtualidad son herramientas que cada docente debe implementar en su quehacer educativo como respuesta a los cambios sociales y laborales que exige un recurso humano calificado y plurilingüe, este, es punto clave para el establecimiento de nexos con entidades comerciales a nivel internacional.

La interculturalidad forma parte del currículo educativo para la enseñanza de toda lengua extranjera, donde el estudiantado desarrolla un sentido de pertenencia social y sea asertivo a otros modos de vida, como enlace de comunicación dirigido al plurilingüismo.

La producción escrita permite al estudiantado descubrir, adquirir y abstraer competencias lingüísticas que le otorguen capacidades para comprender y hacerse comprender mediante la escritura en diferentes escenarios sociales y culturales.

En secundaria, la población estudiantil de noveno año mostró mayor interés por transmitir y divulgar la revista digital en distintas redes sociales, lo cual es una oportunidad de alto rango para la persona docente, al elaborar una mediación

\footnotetext{
${ }^{6}$ Perrine Mignot, Du travail coopératif au collaboratif: un apprentissage plus efficace? (Grenoble: Hal archivesouvertes, 2015), 6, https://dumas.ccsd.cnrs.fr/dumas-01280868/document

7 Mélanie Drouin, Annick Lavoie y Sabrina Héroux, «La Pédagogie Coopérative: Une Approche à redécouvrir»; La Pédagogie Coopérative: Une Approche à redécouvrir», Pédagogie collégiale 25, n. 3 (2012).
} 


\section{Figura 7}

La expresión escrita permite al estudiantado de noveno año contextualizar el uso del idioma francés con su realidad socio-cultural

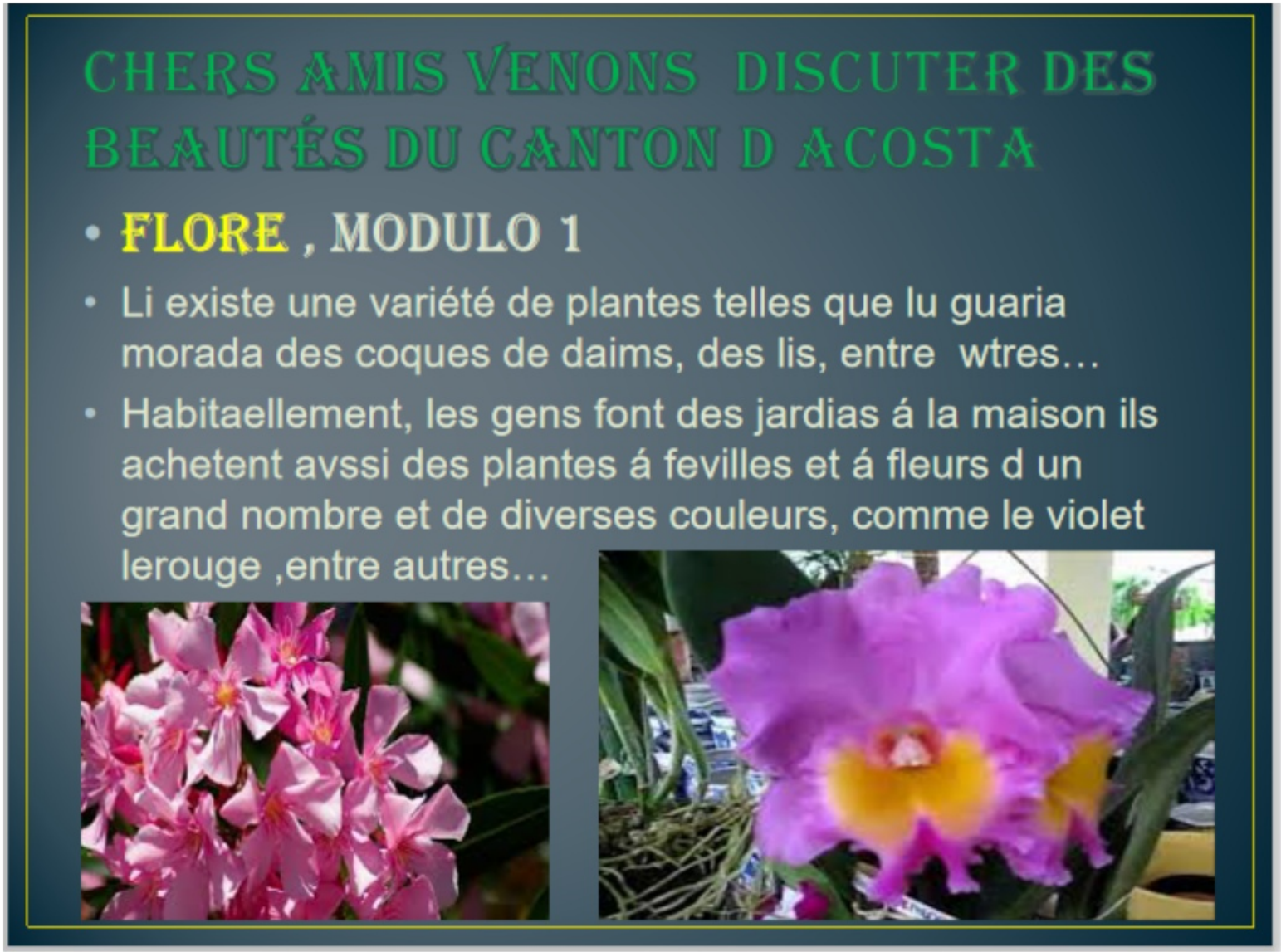

Fuente: Estrategia educativa aplicada al estudiantado de noveno año del Colegio Técnico Profesional de Acosta.

pedagógica atractiva y adaptada a la realidad del alumnado.

El aprovechamiento de capacidades lingüísticas en clases de FLE correlaciona términos y símbolos lingüísticos que determinan la identidad única y diferenciada del interlocutor en su manera de pensar y expresarse de manera clara y puntual.

El aprendizaje de un idioma extranjero debe promocionarse como un saber dinámico que forja el ámbito de la comunicación intercultural y el desarrollo de habilidades sociales, la palabra es un elemento social que se abstrae de manera progresiva en distintos entornos sociales.

Este trabajo final de graduación enfatiza y refuerza la importancia de planificar y aplicar estrategias educativas novedosas que impulsen a la persona estudiante, 
un individuo autosuficiente, disciplinado y de criterio amplio sobre los fenómenos sociales inmediatos.

Una vez más, la UNED como pionera de la transformación curricular renueva la visión y misión en la formación docente para la creación, organización y propuesta de estrategias pedagógicas que forjen saberes con sentido crítico y de manera autónoma, atributos que las nuevas generaciones deben adquirir en aras de construir una sociedad integra y proactiva.

Llevar a cabo este proyecto deja como reflexión que el estudiantado, en secundaria, requiere de la voluntad docente y administrativa para trazar una ruta hacia el enriquecimiento de conocimientos y la producción de nuevos saberes que reafirmen su pertenencia social, y toda herramienta que consolide en alianzas sociales y comerciales a nivel mundial en función del progreso y el bienestar común.

\section{Formato de citación según APA}

Morales-Conejo, C. E. (2021). Fortalecimiento de la expresión escrita francés bajo modalidad colaborativa en el Colegio Técnico Profesional de Acosta. Revista Espiga, 20 (42), 248-265.

\section{Formato de citación según Chicago-Deusto}

Morales-Conejo, César Efrén. «Fortalecimiento de la expresión escrita francés bajo modalidad colaborativa en el Colegio Técnico Profesional de Acosta». Revista Espiga 20, n. .92 (julio-diciembre, 2021): 248-265. 


\section{Referencias utilizadas}

Agama, Emily y Alejandro Martinez. «El fotoperiodismo y los medios de comunicación impresos de la Ciudad de Ambato». Trabajo de graduación previo a la obtención de título de Licenciatura en Comunicación Social. Universidad Técnica de Ambato, 2016. Acceso: 10 de julio de 2019. https:// repositorio.uta.edu.ec/bitstream/123456789/24218/1/FJCS-CS-426.pdf

Araya, Jessica. Estrategia didáctica para el trabajo colaborativo por medio de una red virtual de aprendizaje, con estudiantes de sétimo año del Colegio Miravalles del Circuito Escolar 04 de la Dirección Regional de Educación de Cartago, durante el curso lectivo 2011. Tesis de Licenciatura. Universidad Estatal a Distancia, 2016.

Conseil de l'Europe. Cadre Européen Commun de Référence pour les Langues: Apprendre, Enseigner, Evaluer. Strasbourg ; Unité des Politiques : Unité des Politiques Linguistiques, 2001.

Courtillon, Janine. Élaborer un cours de FLE. Paris: Éditorial Hachette, 2003.

Mignot, Perrine. Du travail coopératif au collaboratif: un apprentissage plus efficace? (Genoble Hal archives-ouvertes Grenoble2015. Acceso: 18 de mayo de 2019. https://dumas.ccsd.cnrs.fr/dumas-01280868/document

Tagliante, Christine. L'évaluation et le Cadre Commun Européen. Techniques et pratiques de classe. Paris: CLE international, 2005.

\section{Referencias consultadas}

Aeby, Sandrime y Jacquin, Marianne. Enseigner la production écrite au secondaire: Quelle articulation entre oral et écrit? Actualité de la recherche en éducation et en formation. Espagne, Université de Genève, AREF 2010.

Al Meriouh, Yousset y Bouyzem, Meriem. La recherche en sciences de gestion: étapes, paradigmes épistémologiques et justification de la connaissance. Revue Économie, Gestion et Société $\mathrm{N}^{\circ} 14$. Ecole Nationale de Commerce et de Gestion de Tanger-Maroc, Maroc, 2017. Acceso: 14 de agosto de 2019. https://www.researchgate.net/publication/ 341121381_LA_RECHERCHE_EN_SCIENCES_DE_GESTION_ETAPES_PARADI GMES_EPISTTEMOLOGIQUES_ETJUSTIFICATIONN_DE_LA_CONNNAISSĀNCE 
Centre d'études sur les jeunes, les médias. Jeunes et médias, Les cahiers francophones de l'éducation aux médias - $n .^{\circ}$ 6: Les Pratiques informationnelles des jeunes dans la presse écrite et en ligne. France: Editorial Publibook, 2014. Acceso: 14 de junio de 2019. https:// books.google.co.cr/books?

$\mathrm{id}=\mathrm{pO} 8 \mathrm{yAwAAQBAJ} \& \mathrm{pg}=\mathrm{PA} 90 \& \mid \mathrm{pg}=\mathrm{PA} 90 \& \mathrm{dq} \# \mathrm{v}=$ onepage $\& q \& \mathrm{f}=$ false

Morales, César. Propuesta metodológica para fortalecer la expresión escrita en el idioma francés dirigido al estudiantado de octavo año mediante el uso de las TICs del Colegio Técnico Profesional de Acosta de la Regional de Desamparados para el periodo lectivo 2017. Trabajo Final de Graduación. San José, Universidad Estatal a Distancia, 2017.

Carballo, Miriam y Guelmes, Esperanza. Algunas consideraciones acerca de las variables en las investigaciones que se desarrollan en educación. Universidad y Sociedad. Revista Científica de la Universidad de Cienfuegos, Cuba, 2016. Acceso: 20 de agosto de 2019. http:// scielo.sld.cu/pdf/rus/v8n1/rus20116.pdf

Doche, Lefco y Lentz, François. Écrire en classe une revue pour la jeunesse. N. ${ }^{\circ}$ 58, mai. Québec, 1985. Acceso: 10 de junio de 2019. https:// www.erudit.org/fr/revues/qf/1985-n58-qf1216379/47782ac.pdf

Fabre, Dominic y Gaye, Dominic. Journaux de lycéens et de collégiens: les enjeux d'une éducation à la citoyenneté. Paris: CLEMI, 1998. Acceso: 25 de setiembre de 2019. https://www.clemi.fr/fileadmin/user_upload/creer-unjournal-scolaire-tableau.pdf

Favar, Monik y Oliver, Thierri. Modèles et méthodes d'étude de la production écrite. Psychologie française. France, 2005. Acceso: 20 de mayo de 2019. http://thierry.olive.pagesperso-orange.fr/resources/2005-Favart-OlivePsyFR.pdf

Gonzalez-Cabrera, Catalina y Ugalde Cecilia. Los nativos digitales y el uso limitado que dan a las herramientas tecnológicas. Universidad de Uzuay (UDA). Azuay, Ecuador, 2014. Acceso: 18 de marzo de 2020. https:// www.researchgate.net/publication/

277132818_Los_nativos_digitales_y_el_uso_limitado_que_dan_a_las_herra

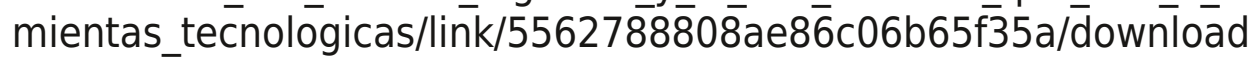

Jacquin, François. La production écrite en lycée: susciter la motivation et développer l'autonomie. Mémoire. Bourgogne, France. Institut Universitaire de Formation de Maîtres, 2005. Acceso: 25 de mayo de 2019. mem2005/05_04STA00055.pdf https://www2.espe.u-bourgogne.fr/doc/memoire/ 
Lamblin, Audrey. Qu'est-ce que la créativité? Comment la développer? Pour quelles finalités? Cycle 1. France. Institut Universitaire de Formation des Maîtres. École interne de I'Université d'Artois, 2012. Acceso: 28 de noviembre de 2019. https://dumas.ccsd.cnrs.fr/dumas-00735191/ document

Mager, Elisabeth. La motivación, punto clave para un aprendizaje más efectivo de un idioma. Relingüística aplicada, N..$^{\circ} 3$ (junio-noviembre). Dialnet, 2005. Acceso: 20 de octubre 2020. http://relinguistica.azc.uam.mx/no003/ articulos/art02.html

Ministère de l'Éducation Nationale, de l'enseignement supérieur et de recherche, CLEMI. Exprimez-vous, créez votre média lycéen! France. Le réseau de création d'accompagnement pédagogique CANOPE, 2015. Acceso: 20 de mayo de 2019. https://www.clemi.fr/fileadmin/user_upload/brochurecreez-votre-media-lyceen.pdf

Polokova, Alexandra. Petit historique du cadre européen commun de référence pour les langues. DELF DALF. Suisse, 2006. Acceso: 10 de agosto de 2019. http://deniscousineau.pbworks.com/f/2.5.2_historique_CECR.pdf

Sihem, Benia. Le rôle de l'écriture créative dans L'enseignement / apprentissage de l'expression écrite en FLE Cas des apprenants de 2AS langues Lycée Othmane Ibn afane M'sila. Mémoire. République Algérienne Démocratique et populaire Université Mohamed Boudiaf- M'Sila, 2017.

Stockinger, Peter. La pratique de la communication sociale. Paris, France, 2007. Acceso: 25 de agosto de 2019. https://www.researchgate.net/publication/ 267626055_La_pratique_de_la_communication_sociale 